\title{
Formation and characterization of $\mathrm{Y}-\mathrm{Al}_{2} \mathrm{O}_{3}$ films produced by oxidation of $\beta-N i A l(110)$ \\ Zf Zhang*, L Li*, Ll Wang***, S I. Sanchez**, Q Wang****, D D. Johnson****, A I. Frenkel**** R G. Nuzzo*** , J C. Yang* \\ * Mechanical Engineering and Materials Science Department, University of Pittsburgh, Pittsburgh, PA 15261 \\ ** Department of Chemistry, University of Illinois at Urbana-Champaign, Urbana, IL 61801 \\ *** Department of Physics, Yeshiva University, New York, New York 10016 \\ **** Department of Materials Science and Engineering, University of Illinois at Urbana-Champaign, Urbana, IL 61801
}

Keyword: Catalyst support, oxidation, $\mathrm{NiAl}, \gamma-\mathrm{Al}_{2} \mathrm{O}_{3}$

$\mathrm{Pt}$ nanoparticles dispersed on $\gamma$-alumina is one of the most widely used heterogeneous catalysis systems used in commercial chemical and energy industries, including petroleum refining[1] and, hence, has been investigated extensively as a model catalyst system to elucidate structure-catalytic activity and selectivity relationships.

Our specific research interest is to understand $\gamma-\mathrm{Al}_{2} \mathrm{O}_{3}$ support affects on the structure and chemistry of the Pt catalyst. Several recent researchers reported that the support determines the structure of the metal catalysts, including size, uniformity and 3-dimensional morphology. For example, recent theoretical simulations revealed that defects in the $\gamma-\mathrm{Al}_{2} \mathrm{O}_{3}$ stabilize the Pt nanoparticles. These simulations are conducted on ideal single crystal $\gamma-\mathrm{Al}_{2} \mathrm{O}_{3}$, whereas commercial $\gamma-\mathrm{Al}_{2} \mathrm{O}_{3}$ is polycrystalline, irregular in shape, and contains impurities (Fig. 1). In order to directly link experiments with theory necessitates the creation of a well-defined, single crystal gamma alumina film. Oxide terraces can be obtained and used as support for metal clusters in model catalytic systems[2]. Previous investigators demonstrated that epitaxial $\gamma-\mathrm{Al}_{2} \mathrm{O}_{3}$ thin film forms on single crystal $\beta-\mathrm{NiAl}$ by oxidation [3], Fig.1b.In this research, $\mathrm{NiAl}$ alloys are used to grow ultrathin $\gamma-\mathrm{Al}_{2} \mathrm{O}_{3}$ layers under well-controlled oxidation conditions. Morphology becomes flatter but more discontinuous during temperature decreasing. Here, we present our results of the oxidation of $\beta-\mathrm{NiAl}(110)$ as a function of oxidation temperature $\left(750-950^{\circ} \mathrm{C}\right)$, time and air flow. The oxide films were characterized by transmission electron microscopy (TEM), scanning electron microscopy (SEM), atomic force microscopy (AFM) and $\mathrm{X}$-ray diffraction (XRD). Plan-view TEM samples were prepared by scratching the oxide off of the surface and placed onto a holey $\mathrm{C}$ grid. Fig. 2 and 3 are the TEM results after NiAl was oxidized for $1 \mathrm{hr}$ at 950 and 850 , respectively. The selected area electron diffraction pattern (SAED) confirmed that the oxide is $\gamma-\mathrm{Al}_{2} \mathrm{O}_{3}$, not another phase of alumina (e.g. theta, delta, alpha). The XRD results confirm that epitaxial (111) $\gamma-\mathrm{Al}_{2} \mathrm{O}_{3}$ plane grows on (110)NiAl substrates (Fig.4). The surface morphology of the oxide films has been examined by SEM (Fig.5). With decreasing temperature, the morphology of the $\gamma-\mathrm{Al}_{2} \mathrm{O}_{3}$ film has become flatter but more discontinuous. The transformation kinetics is accelerated with higher air flowrate. A peculiar ridge network morphology is created which is believed to be a vestige of high diffusivity paths of oxides growth. 
We will deposit Pt particles directly onto $\gamma-\mathrm{Al}_{2} \mathrm{O}_{3}$ surface to examine the interface of $\mathrm{Pt} / \mathrm{Y}-\mathrm{Al}_{2} \mathrm{O}_{3}$ by cross-sectional TEM methods.

\section{Referrences:}

[1]. K. Wefers, Science and Technology Handbook, The American Ceramic Society, 1990, p. 13.

[2]. C.T.Campbell, Surf. Sci. Rep., 27, 1 (1997).

[3]. J. C. Yang, K.N., E. Schumann, M. Riihle, Scripts Metallurgica et Mat\&ah, 1995. 33(7): p. 1043-1048.

[4]. Funded by DOE Basic Energy Sciences (DOE-BES) Catalysis Program (DE-FG02-3ER15476)

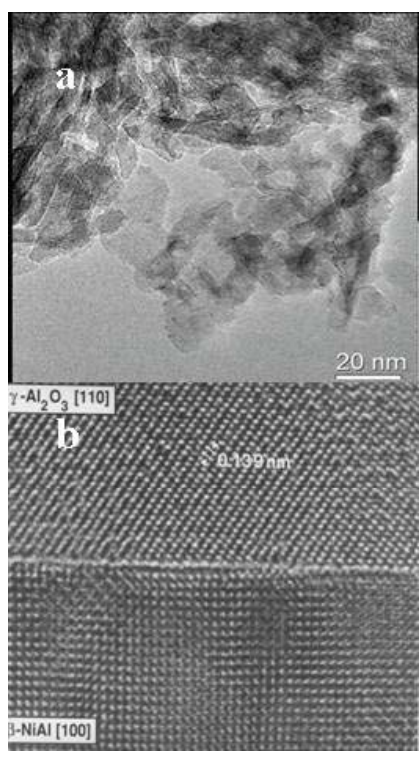

Fig.1 TEM images: a. commercial $\gamma-\mathrm{Al}_{2} \mathrm{O}_{3} . \quad$ polycrystalline b. $\gamma-$ $\mathrm{Al}_{2} \mathrm{O}_{3}(110)$ epitaxial growth on $\operatorname{NiAl}(100)^{[3]}$

Fig.4 XRD of 950 1hour oxidation, eptaxial (111) $\gamma-\mathrm{Al}_{2} \mathrm{O}_{3}$ is found on (110) NiAl

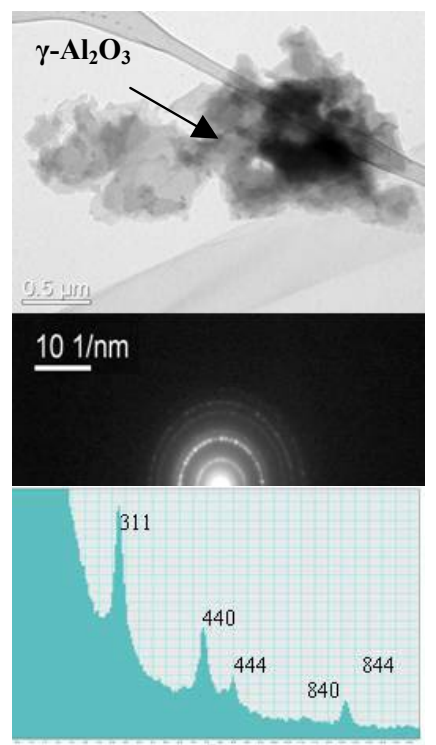

Fig 2 TEM images of 950

1hrs oxidation confirm $\gamma-\mathrm{Al}_{2} \mathrm{O}_{3}$ structure

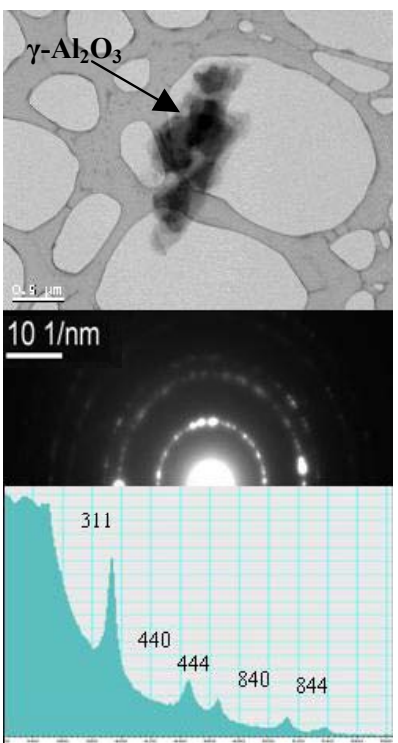

Fig 3 TEM images of 850

lhrs oxidation confirm $\gamma-\mathrm{Al}_{2} \mathrm{O}_{3}$ structure
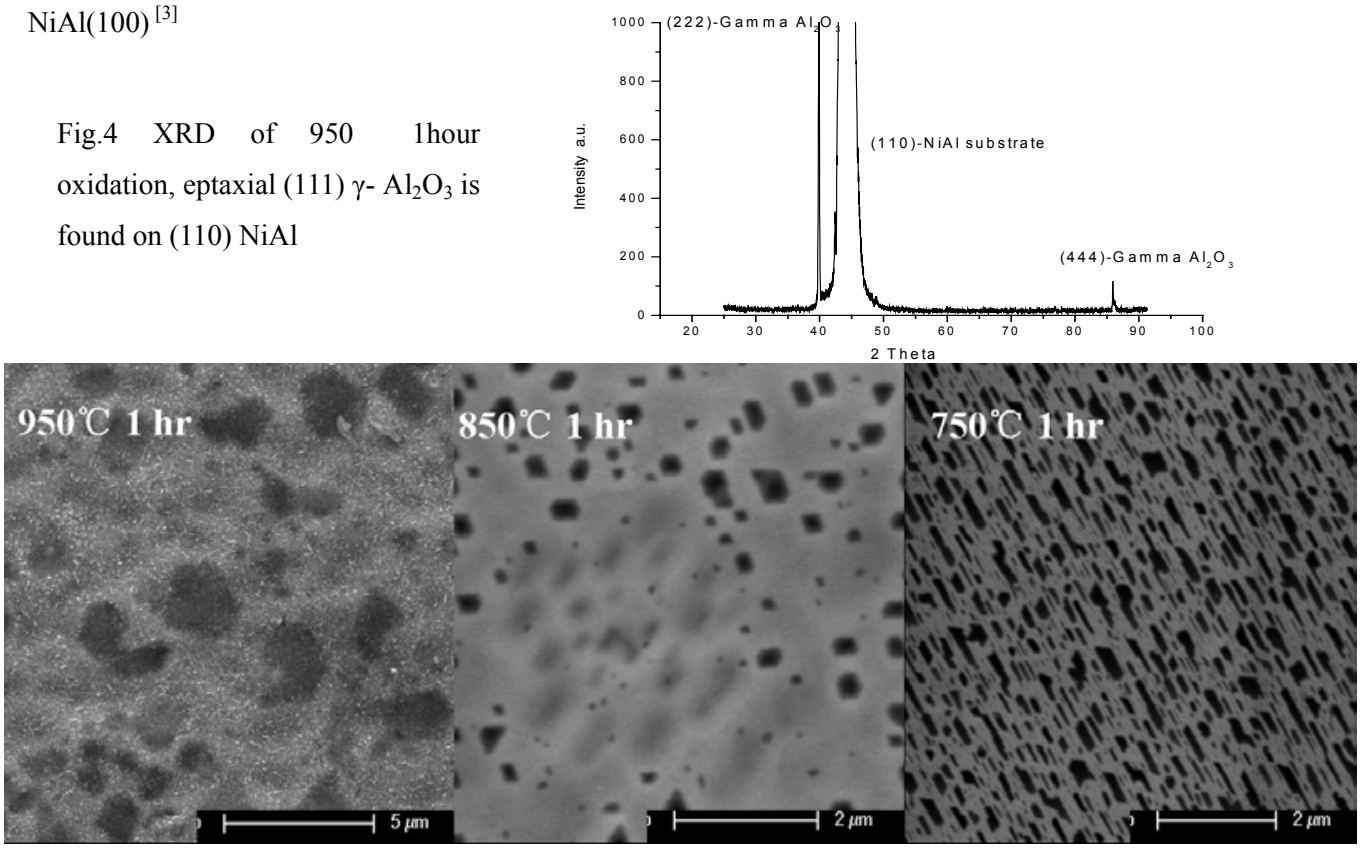

Fig.5 SEM images of $\gamma-\mathrm{Al}_{2} \mathrm{O}_{3}$ on NiAl surface oxidized at $750,850,950^{\circ} \mathrm{C}$ for 1 hour 